ACCEPTED MANUSCRIPT

\title{
Finite element and experimental investigation on the effects of temperature, strain and strain rate on microstructure and mechanical properties of FSSWed TRIP steel joints
}

To cite this article before publication: Ali Ebrahimpour et al 2018 Mater. Res. Express in press https://doi.org/10.1088/2053-1591/aae8f3

\section{Manuscript version: Accepted Manuscript}

Accepted Manuscript is "the version of the article accepted for publication including all changes made as a result of the peer review process, and which may also include the addition to the article by IOP Publishing of a header, an article ID, a cover sheet and/or an 'Accepted

Manuscript' watermark, but excluding any other editing, typesetting or other changes made by IOP Publishing and/or its licensors"

This Accepted Manuscript is (C) 2018 IOP Publishing Ltd.

During the embargo period (the 12 month period from the publication of the Version of Record of this article), the Accepted Manuscript is fully protected by copyright and cannot be reused or reposted elsewhere.

As the Version of Record of this article is going to be / has been published on a subscription basis, this Accepted Manuscript is available for reuse under a CC BY-NC-ND 3.0 licence after the 12 month embargo period.

After the embargo period, everyone is permitted to use copy and redistribute this article for non-commercial purposes only, provided that they adhere to all the terms of the licence https://creativecommons.org/licences/by-nc-nd/3.0

Although reasonable endeavours have been taken to obtain all necessary permissions from third parties to include their copyrighted content within this article, their full citation and copyright line may not be present in this Accepted Manuscript version. Before using any content from this article, please refer to the Version of Record on IOPscience once published for full citation and copyright details, as permissions will likely be required. All third party content is fully copyright protected, unless specifically stated otherwise in the figure caption in the Version of Record.

View the article online for updates and enhancements. 


\title{
Finite element and experimental investigation on the effects of temperature, strain and strain rate on microstructure and mechanical properties of FSSWed TRIP steel joints
}

\author{
Ali Ebrahimpour ${ }^{* 1}$, Amir Mostafapour ${ }^{2}$, Kaveh Samadian ${ }^{3}$ \\ 1-Mianeh Technical and engineering Faculty, University of Tabriz, Tabriz, Iran \\ 2- Faculty of Mechanical Engineering, University of Tabriz, Tabriz, Iran \\ 3-Labo Soete, Department of Electrical Energy, Metal, Mechanical Constructions and systems, Ghent \\ University, Belgium
}

\begin{abstract}
FSSWed TRIP steel joints were investigated at four rotational speed of 900, 1200, 1500 and $1800 \mathrm{rpm}$. A finite element model was developed to obtain thermal history, strain and strain rate during welding and the results validated by experimental data. The microstructure, microhardness distribution and shear tensile strength were examined. The FSSW process successfully produced high integrity completely defect-free joints at all the proposed welding parameters. As a result of temperature and strain distribution imposed by process, three different zones were determined in welding region: stir zone with recrystallized structure, thermomechanical affected zone with major phase of martensite and heat affected zones. The maximum microhardnees was achieved at stir zone and decreased by getting away from keyhole. Totally the microhardness increased by increasing rotational speed. It was obtained that the strength of joints increased to a maximum value of $9.9 \mathrm{kN}$ in $1500 \mathrm{rpm}$ and then decreases to $8.4 \mathrm{kN}$ at $1800 \mathrm{rpm}$. By increasing rotational speed, the strain rate increased and causes to recrystallization of the prior austenite grains, but in high rotational speed, the higher temperature causes to grain growth in recrystallized grains. The fracture surfaces of joints showed a dimple pattern ductile fracture in all cases except $1800 \mathrm{rpm}$ that the fracture was less ductile which agrees with lower tensile elongation of it.
\end{abstract}

Key words: Friction stir spot welding; TRIP steel; Finite element modeling; Microstructure;

\section{Introduction}

Transformation induced plasticity (TRIP) steel is one of the advanced high strength steels (AHSS) that has a multiphase microstructure contained ferrite, martensite, bainite and austenite. The presence of retained austenite in the microstructure of this steel which during deformation, transforms to martensite

${ }^{1}$ Corresponding author: aliebrahimpour414@gmail.com 
results in good mechanical properties such as high strength and good ductility and high energy absorption during car crash[1]; Therefore, the appliction of this type of steel in the industry, especially in the automotive industry is facing a significant increase.

One of the limitations to increase the using of these steels is welding of them. Because fusion welding methods cause to melt of weld zone and their unique microstructure is destroyed. The joining of TRIP steel is in high demand considering the application of them and consequently, the related strength and ductility drop off $[1,2]$.

The bases of friction stir spot welding (FSSW) is on the fundamentals of friction stir welding (FSW) [3] and consisting of only the plunge, dwell and retract stages of FSW [4] and is suggested to substitute for the resistance spot welding. FSSW is a solid-state method and the maximum temperature does not increase to melt point during welding that prevents the formation of coarse grains and solidification defects.

It is reported that the thermal history and degree of deformation have significant influence on the microstructures of FSSWed TRIP steels [5, 6]. Since the calculation of the thermal history and deformation during FSW/FSSW is expensive and time consuming, only a few experimental investigations were focused on thermomechanical parameters in FSW/FSSW [7-9], and majority of the researchers have implemented the numerical methods in this regard. To find comprehensive information on the using of finite element methods in simulation of FSW/FSSW, readers are referred to[10].

Reviewing the previously published studies indicates lack of investigating the effect of thermomechanical parameters on properties of FSSWed TRIP steel joints; Therefore, in this investigation, effects of thermomechanical parameters of FSSW on TRIP steel were studied by experimental and finite element methods.

As the rotational speed plays a very important role in FSSW [11], it was changed in a constant dwell time and plunge depth during welding for investigation of the effect of thermomechnical parameters. A fully coupled 3D finite element model was used to obtain the thermal history and strain and strain rate distribution in all cases. Finally, the effects of thermomechanical parameters investigated using finite element results (thermal history, strain and strain rate), microstructure observation (Optical microscopy (OM), Field emission scanning electron microscopy (FE-SEM), electron backscattered diffraction (EBSD) technique and X-ray diffraction (XRD)) and measurement of mechanical properties (lap shear tensile strength and microhardness). 


\section{Materials and Methods}

The chemical composition of the steel used in this study is: $0.21 \mathrm{C}, 1.5 \mathrm{Si}, 1.68 \mathrm{Mn}, 0.03 \mathrm{Cr}, 0.016 \mathrm{Al}$, $0.01 \mathrm{Ni}$ and $0.009 \mathrm{~S}$ (wt. \%). The phase transformation temperatures were calculated using ThermoCalc software and the values of $705{ }^{\circ} \mathrm{C}$ and $836{ }^{\circ} \mathrm{C}$ obtained for $A c_{1}$ and $A c_{3}$ respectively.

Four joint at rotational speed of 900, 1200, 1500 and $1800 \mathrm{rpm}$ and constant dwell time (2 s) and plunge depth $(2 \mathrm{~mm})$ were investigated. For each joint, two TRIP steel sheets with dimension of $100 \times 30 \times 1.2 \mathrm{~mm}$ were prepared under a special heat treatment route [6] and then FSSWed by $35 \mathrm{~mm}$ of overlapping (Figure 1(a)). A special fixture was designed and manufactured to keep sheets during welding. Also, FSSW was done by a tungsten carbide tool with dimensions of $10 \mathrm{~mm}, 5 \mathrm{~mm}$ and 1.9 $\mathrm{mm}$ respectively for shoulder diameter, pin diameter and pin length. Figure 1(b) shows the tool that used in this research.

For the OM investigations, it was obtained that the metabisulfite solution $\left(\mathrm{Na}_{2} \mathrm{~S}_{2} \mathrm{O}_{3} \cdot \mathrm{H}_{2} \mathrm{O} 10 \mathrm{~g}+\mathrm{H}_{2} \mathrm{O}\right.$ $100 \mathrm{ml}$ ) is the best etchant solution and the all of phases can be determined using it [12]. EBSD was performed with an EDAX/TSL EBSD system. The acceleration voltage during EBSD data collection was $12-15 \mathrm{kV}$, beam current $2.5-5.5 \mathrm{nA}$, the working distance $8 \mathrm{~mm}$ and the step size $20-60 \mathrm{~nm}$. The TSL OIM software was used to analysis of EBSD output file/which contains several automated functions for characterization of EBSD maps.

The amount of austenite phase and carbon content of it were measured by XRD using $\mathrm{Cu}-\mathrm{K} \alpha$ radiation. A step scan within the $2 \theta$ interval between $40^{\circ}$ and $120^{\circ}$ at $0.2^{\circ}$ was done. XRD investigations were done with $\mu$-XRD collimators to obtain a narrow X-ray beam for a local measurement.

Vickers microhardness was measured under the load of $100 \mathrm{~g}$. The microhardness tests were carried out at a distance of $0.5 \mathrm{~mm}$ from the top surface of the upper plate. Strength of the joints was measured by lap shear tensile test and the fracture surfaces were investigated using FE-SEM micrograph. Moreover, for finite element modeling, the ABAQUS software package was utilized, which previously has been used for FSW/FSSW simulations [13]. Finite element modeling was performed at rotational speed of 900, 1200, 1500 and $1800 \mathrm{rpm}$ and thermal history and strain and strain rate distribution were obtained in all models. The details of the finite element model and the temperature dependent properties of the BM have been presented in the previous work of the authors of this paper [5,6].

For finite element outputs validation the thermal histories of some points at one case (1200 rpm) were recorded K-type thermocouple. For this purpose a special set of sheets was prepared. Figure 1 shows the schematic of the thermocouples location at the special welding set. 
Figure 2 compares the maximum temperatures that are obtained by measurement and finite element modeling. As is clear from this figure the finite element result are in good agreement with experimentally measured results.

\section{Results and discussion}

The inverse pole figure (IPF) map of the BM is represented in Figure 3(a). Average grain size of $7 \mu \mathrm{m}$, as measured using the linear intercept method (ASTM E112). Figure 3(b) contains high angle grain boundaries (HAGBs) and image quality map (IQ). The IQ map can be used to identify the martensite and bainite phases in carbon steels [14]. It is reported that the regions with lower image quality (dark regions) are martensite or bainite [14]. Part of the martensite phase shown in Figure 3(b), in fact, is the retained austenite that has transformed to martensite during preparation. It can be proved by XRD result that measured 13 percent of retained austenite in BM (Table 1). OM microstructure of BM is presented in Figure 4 (a). The ferrite grains with light gray appearance are the major phase of BM. Retained austenite grains can be appeared in two morphologies: blocks and films [15] . As can be seen from OM microstructure both morphologies of austenite observed in BM. Bainite and martensite are the dark regions in the OM. Similar observations have been reported in previous studies [15].

Figure 5(a) shows the section views of experimental joints. The welding region can be subdivided to three zones by appearance of various colors under the optical microscopy after macro-etching: stir zone (SZ), thermo-mechanical affected zone (TMAZ) and heat affected zone (HAZ). In previous scientific literature, the researchers have reported the forming of three subdivided zones in FSSW/FSW of TRIP steel $[1,16]$.

The distribution of temperature and strain in all finite element models are shown in Figure 5(b). The maximum achieved strains are 7.2, 7.9, 8.7 and 9.9 respectively. Although the values reported for strain in the previous studies are very scattered, but in the similar conditions of this study, the values reported for the strain are $1-10[7,9,17]$. The maximum values of temperature in the cases are 940 , 1020,1105 and $1150^{\circ} \mathrm{C}$. According to the results of simulated model, temperature, strain and strain rate have maximum values near the pin. All the results of strain, strain rate and temperature obtained during welding are in good agreement with previously reported data [6].

The OM microstructure of welding zones related to case welded at $1200 \mathrm{rpm}$ is represented in Figure 4 (b, c and d). The various phases determined by different colors after color etching.

The microstructure of HAZ includes ferrite, austenite, bainite and martensite. Although, the austenite phase in the Figure 4(b) is not visible clearly, the presence of austenite in the HAZ was proved by the 
XRD result. Mozzaffero et al. [1] reported the formation of multiphase heat affected zone which contains ferrite, retained austenite, martensite and bainite, during FSSW TRIP steel sheets with similar chemical competition. The volume fraction of retained austenite and its carbon content in subdivided zones of all cases that measured by XRD are given in Table 1.The results showed that the retained austenite of HAZ and carbon content of this zone increased at rotational speed from $900 \mathrm{rpm}$ to 1500 $\mathrm{rpm}$ and then decreased in $1800 \mathrm{rpm}$. The fraction of retained austenite in HAZ was lower than BM in all samples. It can be concluded that the carbon diffusion from bainite to fcc phase (austenite) during heating take places in the HAZ. During cooling the ferrite grain growth causes rejection of carbon to austenite. Increasing the amount of carbon increases the austenitic stability. The lower retained austenite of HAZ in case $1800 \mathrm{rpm}$ can be related to the higher temperature that occurs during welding which causes the growth of austenite grains in intercritical region. The bigger austenite grains decreases the thermal stability of its [18].

Using OM, only the ferrite and martensite phases observed clearly in the TMAZ (Figure 4(c)) but austenite and bainite identified using FE-SEM. Figure 6 shows the FE-SEM microstructure of TMAZ. In SEM microstructure the ferrite can be determined by black and un-etched appearance $[14,16]$. The regions with lamellar structure that contain bainitic ferrite and austenite are bainite $[14,16]$. Austenite can be observed by smooth appearance. Also, lath martensite can be determined by rough appearance. Existence of these phases in TMAZ, proves that the metal was heated to the maximum temperature between $A c_{3}$ and $A c_{1}$, where ferrite and austenite coexist and Figure 2 supports this deduction. Formation of bainite and martensite from some austenite grains occur during the cooling. Furthermore, it seems that the microstructure of TMAZ was relatively deformed as a result of deformation forced by the FSSW. The finite element data proved deformation of material in TMAZ (Figure 5). This is supportive for mechanical stabilization of the austenite because the higher dislocation densities in grains causes increasing stacking fault energy and results to reduction of driving force for formation of martensite [19]. It is stated that dynamic recovery, dynamic recrystallization and strain-induced ferrite transformation are the main mechanisms for the small ferrite grains formation in the TMAZ [20]. The XRD results showed the amount of retained austenite in case $1200 \mathrm{rpm}$ about 4.5 percent. According to Table 1, in TMAZ, higher rotation speed resulted more retained austenite with higher carbon content. Basuki and Aernould [21] stated that the strain in intercritical temperature increases the rate of bainite nucleation owing to defects imposed to austenite; however, as the bainite plate grows, carbon is rejected to residual austenite. Higher rotational speed causes lower cooling rate and provides more time for carbon diffusion in austenite. 
According Figure 4(d) the major phase of SZ is lath martensite. However, presence of some allotriomorphic ferrite and widmanstatten ferrite grains can be proven by this figure. Researchers have reported presence of allotriomorphic ferrite and widmanstatten ferrite within lath martensite field in FSSW of TRIP steel $[1,6,14]$. In FSSW, the microstructure of SZ completely changes to austenite because of peak temperature of higher than $\mathrm{Ac}_{3}$. It is possible that discontinues dynamic recrystallization (DDRX) of austenite occurs in this zone due to high temperature and intense deformation. The formation of ferrite and martensite, indicate that the temperature has risen above $A c_{3}$ during heating and the cooling rate was slower than the critical rate for the resulted completely martensitic microstructures.

Unlike FSW which the microstructure of all zones has an effect on the final strength of joint, in FSSW, the joined region (is known as the bonding ligament width) is mostly within the SZ and the final strength of the joint depends to the microstructure of this zone. The FE-SEM microstructure of the SZs are supplied in Figure 7(a-d) and the related thermal histories and cooling rates are given in Figure 8. A comparison of the micrographs indicated that a larger amount of allotriomorphic ferrite was formed by increasing the tool rotational speed. Also, a significant increasing of heterogeneity in grain sizes can be seen by increasing rotational speed. It suggests that higher strain and temperature caused a recrystallization of the steel. However, the time for processing was not sufficient to obtain a totally recrystallized microstructure. Although there was a lower ferrite nucleation rate in slower rotational speed, it can be seen from microstructures that ferrite grain sizes are larger in faster rotational speed. It suggests that higher peak temperature associated with the slower cooling rate in faster rotational speed facilitated the diffusional process of allotriomorphic ferrite growth. The results express an increase in temperature and strain; however, cooling rate has decreased by increasing rotational speed. The formation of widmanstatten ferrite, bainite and martensite is easier in faster cooling rates because of lack of time for diffusion of carbon. An increasing in strain causes the formation of allotriomorphic ferrite. In fact, deformation increases the austenite grain boundaries and/or reduces the undercooling that is essential for its nucleation [22]. Dynamic recrystallization of austenite in SZ of FSSWed TRIP, TWIP and stainless steels has been reported in previous studies [1, 2, 23, 24]. The result of XRD confirms the presence of about 2-3 percent of martensite in SZ for probable cases.

Figure 9 displays the microhardness of the zones at all the welds. Microhardness at SZs was higher with respect to the base alloy. The enhancement was associated with the simultaneous effects of fine grain size and formation of martensite at SZs. FSSW of $0.24 \mathrm{C}+1.6 \mathrm{Al}+2 \mathrm{Mn}+0.3 \mathrm{Si}$ TRIP steel stated the hardness of 400-550 VHN at SZ for fully martensite microstructure [2]. An average microhardness 
of $480 \mathrm{VHN}$ at SZ has been testified by mazzaferro et al. [1] for FSSWed TRIP steel with similar composition of the this study, where SZ consisted of ferrite, bainite and martensite. The peak hardness achieved in this study was 512 VHN that is close to the above mentioned instances. It can be almost stated that hardness increased with rotational speed. Comparing to SZ, the microhardness of TMAZ was lower due to lower martensite. Decreasing of microhardness was continued by transition to HAZ, but still the VHN was high in comparison to the base metal. However, Figure 9 shows a microhardness less than BM at the HAZ near the BM. It can be attributed to the temperature of this point. When the temperature is less than $A c_{1}$, it may be induce tempering of the martensite of $\mathrm{BM}$; this will result in decreased hardness as well [25].

The most important parameter that affects the strength of the joint is the region where the two sheets being joined and is known as the bonding ligament width. The bonding ligament widths of the cases $1200 \mathrm{rpm}$ and $1800 \mathrm{rpm}$ are provided in Figure10. In some of the previous studies [2, 23], it has been reported that there is no correlation between the rotational speed and bounding ligament width, but in the present study, it was found that by increasing the rotational speed from $900 \mathrm{rpm}$ to $1800 \mathrm{rpm}$, the bonding ligament width increased from $210 \mu \mathrm{m}$ to $350 \mu \mathrm{m}$. In fact, a high rotational speed results in more extensive stirring and input heat; therefore, the larger stir zone and consequently the wider bonding ligament is formed.

Figure 11 represents the responses of the lap shear tensile tests for the studied samples. The strength of the joint in the sample joined at $900 \mathrm{rpm}$ were about 7.6 KN. As the rotational speed increased, the strength increased up to a maximum value of $9.5 \mathrm{KN}$ at rotational speed of $1500 \mathrm{rpm}$ and then decreased to $8.4 \mathrm{KN}$ at $1800 \mathrm{rpm}$. It can be related the microstructure of the bonding ligament width at the case $1800 \mathrm{rpm}$. In fact, the strain rate and input heat are higher in higher rotational speeds and this is the reason of more stirring in the SZ. For the estimation of recrystallized prior austenite grain size (d) the Zener-Hollomon parameter (Z) can be used as follows [26]:

$Z=\dot{\varepsilon} E X P\left(\frac{Q}{R T}\right)$

$d=k\left(\frac{Z}{A}\right)^{-p}$

Where $\dot{\varepsilon}$ and $\mathrm{T}$ are strain rate $\left(s^{-1}\right)$ and absolute temperature $\left({ }^{\circ} \mathrm{K}\right) . \mathrm{R}$ is the constant and equal to 8.314 $\left(\frac{\mathrm{J}}{{ }^{\circ} \mathrm{K} \mathrm{Mol}}\right) \cdot \mathrm{Q}$ is the actiyation energy $(\mathrm{J} / \mathrm{Mol})$ and can be obtained as follows [27]:

$Q=267000-2535 \% \mathrm{C}+1010 \% \mathrm{Mn}+33620 \% \mathrm{Si}$

Also, The value of A can be calculated from the equation below [28]:

$$
A\left(s^{-1}\right)=(12.197+65.59 \% C) \exp \left(7.076 \times 10^{-5} Q\right)
$$


For the steel of present study the values of the Q and A calculated $315(\mathrm{~kJ} / \mathrm{Mol})$ and $1.21 \times 10^{11}\left(s^{-1}\right)$. $\mathrm{k}$ and $\mathrm{p}$ are dependent on material properties. Finally, knowing the strain rate that obtained from finite element modeling in the bonding region of all cases the grain size can be calculated. The average grain size of $4.5 \mu \mathrm{m}$ calculated for the prior austenite was calculated in the case welded under rotational speed of $1500 \mathrm{rpm}$, which confirm occurring a high level DDRX during welding. This calculated result is in good agreement with the data that is reported in the previous scientific literature $[14,16]$. Figure 11 shows the strength of joint with recrystallized prior austenite grain size, peak temperature and average strain rate experienced by bonding region in all cases. As is clear from the Figure 11, the grain size of prior austenite decreases with increasing rotational speed from $5.7 \mu \mathrm{m}$ at $900 \mathrm{rpm}$ to a minimum value of $4.5 \mu \mathrm{m}$ at $1500 \mathrm{rpm}$ and then increases up to $5 \mu \mathrm{m}$ at $1800 \mathrm{rpm}$. The increasing of rotational speed have two contradictory effects on grain size of prior austenite. When the rotational speed increases, higher level of strain rate imposes to steel and $\mathrm{Z}$ parameter increases according to the equations (1) and (2) which causes to formation of smaller grains of prior austenite. According to previous reports, smaller prior austenite lead to decrease of the packet size of lath martensite; therefore the strength of microstructure increases [29]. On the other hand, by increasing the rotational speed, the peak temperature increases. However, in the case welded at $1800 \mathrm{rpm}$ the harmful influence of temperature increasing destroys the helpful influence of strain rate and the $\mathrm{Z}$ parameter declines, which results in larger prior austenitic grains. Finally, the microstructure with large packet lath martensite causes to reduction of the strength. It is obvious from the microstructures of SZs (Figure 7), increasing the rotational speed results in martensite with larger packets in the stirred region.

Mazzaferro [1] and Lomholt [2] have reported that the failure of FSSWed TRIP steels occurs at SZ. It has also reported that the fracture of TRIP steel joint is ductile [1, 2]. The fracture surfaces of cases welded at rotational speed of $1500 \mathrm{rpm}$ and $1800 \mathrm{rpm}$ are shown in Figure 12. It is obvious that the fracture surface of the $1500 \mathrm{rpm}$ case has shown a ductile behavior with uniform dimple sizes. In the sample joined at $1800 \mathrm{rpm}$ the fracture surface was slightly distinct from the rest of cases where it has not revealed a dimple pattern. In this case, the fracture has shown less ductility that agrees with lower tensile elongation of it.

\section{Conclusions}

In this paper, fiction stir spot welding of TRIP steel sheets was investigated under rotational speed of 900, 1200, 1500 and $1800 \mathrm{rpm}$. Using finite element modeling the temperature, strain and strain rate 
during welding were calculated and the effect of these parameter were studied on properties of joints. The following results were obtained:

- The maximum achieved strains in the cases welded under rotational speed of 900, 1200, 1500 and $1800 \mathrm{rpm}$ was 7.2, 7.9, 8.7 and 9.9 respectively. In addition, the maximum values of temperature in the cases was $940,1020,1105$ and $1150^{\circ} \mathrm{C}$. According to the results of simulated model, temperature, strain and strain rate have maximum values near the pin.

- The results of finite element modeling showed that when the rotational speed increased, the temperature, strain and strain rate increased and the cooling rate decreased.

- Considering thermal cycles and strain forced by the welding, three different zones were formed in the welds, including: SZ, TMAZ, and HAZ.

- The volume fraction of retained austenite in base metal and subdivided zones was measured by XRD. The results showed a reduction from $13 \%$ in BM to minimum value of $2-3 \%$ in SZ.

- The most important parameter that affects the strength of the joint was the region where the two sheets being joined and is known as the bonding ligament width. By increasing the rotational speed, the bonding ligament width increased.

- The calculation of prior austenite grain size was done using finite element data and the results confirmed occurring of discontinues dynamic recrystallization (DDRX) of austenite. The grain size of prior austenite decreased with increasing rotational speed from $5.7 \mu \mathrm{m}$ at $900 \mathrm{rpm}$ to a minimum value of $4.5 \mu \mathrm{m}$ at $1500 \mathrm{rpm}$ and then increased up to $5 \mu \mathrm{m}$ at $1800 \mathrm{rpm}$.

- By increasing the rotational speed, the tensile strength of the joints at first increased up to a maximum value of $9.9 \mathrm{KN}$ in rotational speed of $1500 \mathrm{rpm}$ and then decreased. In fact, higher rotational speed causes more stirring of the metal and consequently more recrystallization of it. Therefore, the grain size of the stir zone undergoes into a higher level of refinement that causes higher strength of the joint. On the other hand, in high rotational speed more input heat generated and the recrystallized grains begin growing. Therefore, in maximum rotation speed the strength reduced.

- The fracture micrographs of the welds showed a dimple pattern ductile fracture except the joint welded at $1800 \mathrm{rpm}$ that the fracture was less ductile and agrees with lower tensile the lower tensile elongation of it. 


\section{References}

[1] C. Mazzaferro, T. Rosendo, M. Tier, J. Mazzaferro, J. Dos Santos, and T. Strohaecker, "Microstructural and mechanical observations of galvanized TRIP steel after friction stir spot welding," Materials and Manufacturing Processes, vol. 30, no. 9, pp. 1090-1103, 2015.

[2] T. C. Lomholt, Y. Adachi, J. Peterson, R. Steel, K. Pantleon, and M. A. Somers, "Microstructure characterization of friction stir spot welded TRIP steel," Advanced Materials Research, vol. 409, pp. 275-280, 2011.

[3] W. M. Thomas, E. D. Nicholas, J. C. Needham, M. G. Murch, P. Temple-Smith, and C. J. Dawes, "Friction-stir butt welding

" UK, 1991.

[4] G. Pieta, J. dos Santos, T. Strohaecker, and T. Clarke, "Optimization of friction spot welding process parameters for AA2198-T8 sheets," Materials and Manufacturing Processes, vol. 29, no. 8, pp. 934-940, 2014.

[5] A. Mostafapour, A. Ebrahimpour, and T. Saeid, "Numerical and experimental study on the effects of welding environment and input heat on properties of FSSWed TRIP steel," The International Journal of Advanced Manufacturing Technology, vol. 90, no. 1-4, pp. 1131-1143, 2017.

[6] A. Mostafapour, A. Ebrahimpour, and T. Saeid, "Finite element investigation on the effect of FSSW parameters on the size of welding subdivided zones in TRIP steels," The International Journal of Advanced Manufacturing Technology, vol. 88, no. 1-4, pp. 277-289, 2017.

[7] M. Nourani, A. S. Milani, and S. Yannacopoulos, "On the Experimental and Numerical Predictions of Strain during Friction Stir Welding: A Case Study on 7050 Aluminum Alloy," Transaction on Control and Mechanical Systems, vol. 1, no. 6, pp. 259-263, 2012.

[8] Z. Chen and S. Cui, "Strain and strain rate during friction stir welding/processing of Al-7Si$0.3 \mathrm{Mg}$ alloy," in IOP Conference Series: Materials Science and Engineering, 2009, vol. 4, no. 1, p. 012026: IOP Publishing.

[9] A. Arora, Z. Zhang, A. Deb, and T. DebRoya, "Strains and strain rates during friction stir welding," Scripta Materialia, vol. 61, pp. 863-866, 2009.

[10] X. He, F. Gu, and A. Ball, "A review of numerical analysis of friction stir welding," Progress in Materials Science vol. 65, pp. 1-66, 2014.

[11] P. Ganesh and V. S. Kumar, "Superplastic Forming of Friction Stir Welded AA6061-T6 Alloy Sheet with Various Tool Rotation Speed," Materials and Manufacturing Processes, vol. 30, no. 9, pp. 1080-1089, 2015.

[12] E. Girault, "Metallographic Methods for Revealing the Multiphase Microstructure Of TRIPAssisted Steels," Materials Characterization, vol. 40, no. 2, pp. 111-118, 1998.

[13] X. He, F. Gu, and A. Ball, "A review of numerical analysis of friction stir welding," Progress in Materials Science, vol. 65, pp. 1-66, 2014.

[14] T. C. Lomholt, K. Pantleon, and M. A. Somers, "Microstructure evolution during friction stir spot welding of TRIP steel," DTU Mekanik, Internet: http://www. mek. dtu. dk/Forskning/Projekter-phd/phd_trinecoldinglomholt. aspx, vol. 24, 2011.

[15] Y.F.Shena, L.N.Qiu, X.Sun, L.Zuo, P.K.Liawc, and D.Raabe, "Effects of retained austenite volume fraction, morphology, and carbon content on strength and ductility of nano structured TRIP-assisted steels " Materials Science \& EngineeringA, vol. 636, pp. 551-564 2015.

[16] S. Mironov, Y. Sato, S. Yoneyama, H. Kokawa, H. Fujii, and S. Hirano, "Microstructure and tensile behavior of friction-stir welded TRIP steel," Materials Science and Engineering: A, vol. 717, pp. 26-33, 2018. 
[17] Z. W. Chen and S. Cui, "Strain and strain rate during friction stir welding/processing of Al-7 $\mathrm{Si}-0.3 \mathrm{Mg}$ alloy," in IOP Conference Series Materials Science and Engineering vol. 4, ed, 2009, p. 012026.

[18] G. Reisner, E. Werner, P. Kerschbaummayr, I. Papst, and F. Fischer, "The modeling of retained austenite in low-alloyed TRIP steels," JOM, vol. 49, no. 9, pp. 62-65, 1997.

[19] J. Wan, S. Chen, and T. Y. Hsu, "Effect of stacking fault energy and austenite strengthening on martensitic transformation in Fe-Mn-Si alloys," Journal of Physics IV, vol. 381-384, p. 112, 2003.

[20] R. Song, D. Ponge, D. Raabe, J. Speer, and D. Matlock, "Overview of processing, microstructure and mechanical properties of ultrafine grained bcc steels," Materials Science and Engineering: A, vol. 441, no. 1, pp. 1-17, 2006.

[21] A. Basuki and E. Aernoudt, "Influence of rolling of TRIP steel in the intercritical region on the stability of retained austenite," Journal of Materials Processing Technology, vol. 89, pp. 3743, 1999.

[22] H. Bhadeshia and L. Svensson, "Mathematical modelling of weld phenomena III," Institute of Materials, London, vol. 229, 1997.

[23] M. Ahmed, E. Ahmed, A. Hamada, S. Khodir, M. E.-S. Seleman, and B. Wynne, "Microstructure and mechanical properties evolution of friction stir spot welded high-Mn twinning-induced plasticity steel," Materials \& Design, vol. 91, pp. 378-387, 2016.

[24] M. Hajian et al., "Microstructure and mechanical properties of friction stir processed AISI 316L stainless steel," Materials \& Design, vol. 67, pp. 82-94, 2015.

[25] A. K. Sinha, Physical Metallurgy Handbook. McGraw-Hill, 2002.

[26] L.-J. Zhu, W. Di, and X.-M. Zhao, "Recrystallization modelling of hot deformed Si-Mn TRIP steel," Journal of Iron and Steel Research, International, vol. 14, no. 2, pp. 61-65, 2007.

[27] S. F. Medina and C. A. Hernandez, "General expression of the Zener-Hollomon parameter as a function of the chemical composition of low alloy and microalloyed steels," Acta materialia, vol. 44, no. 1, pp. 137-148, 1996.

[28] S. Medina and C. Hernandez, "Modelling of the dynamic recrystallization of austenite in low alloy and microalloyed steels," Acta materialia, vol. 44, no. 1, pp. 165-171, 1996.

[29] J. Hidalgo and M. J. Santofimia, "Effect of Prior Austenite Grain Size Refinement by Thermal Cycling on the Microstructural Features of As-Quenched Lath Martensite," Metallurgical and Materials Transactions A, pp. 1-14, 2016. 


\section{Figure captions}

Figure 1 (a) The schematic of the thermocouples positions in specimen and (b) the FSSW tool which used in present study

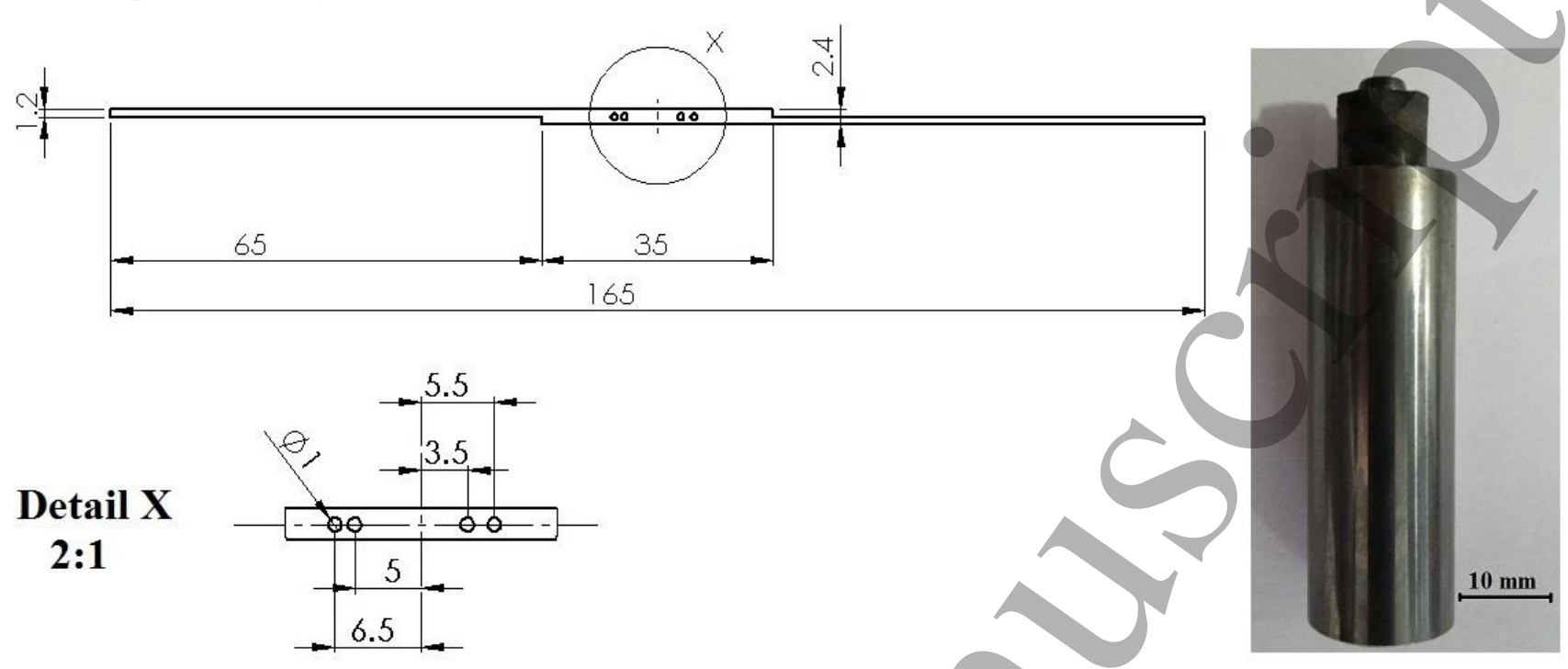

(a)

(b) 
Figure 2 Comparisons between numerical and experimental peak temperatures, in cases which welded under rotational speed of $1200 \mathrm{rpm}$. The data were obtained at the end of dwell time and distances of $3,5,5.5$ and $6.5 \mathrm{~mm}$ from the pin center.

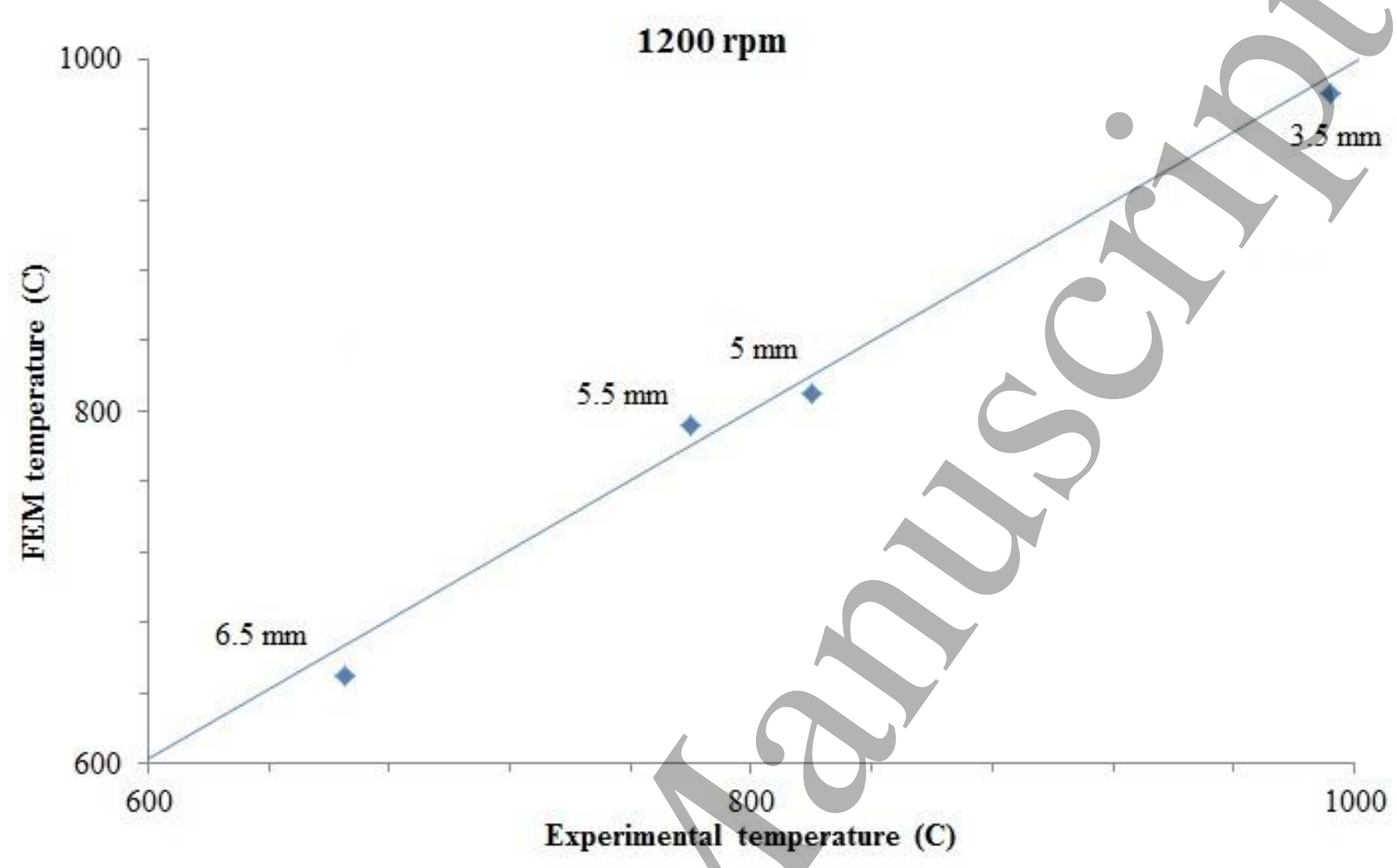


Figure 3 (a) IPF map of BM, and (b) HAGBs and IQ map in BM
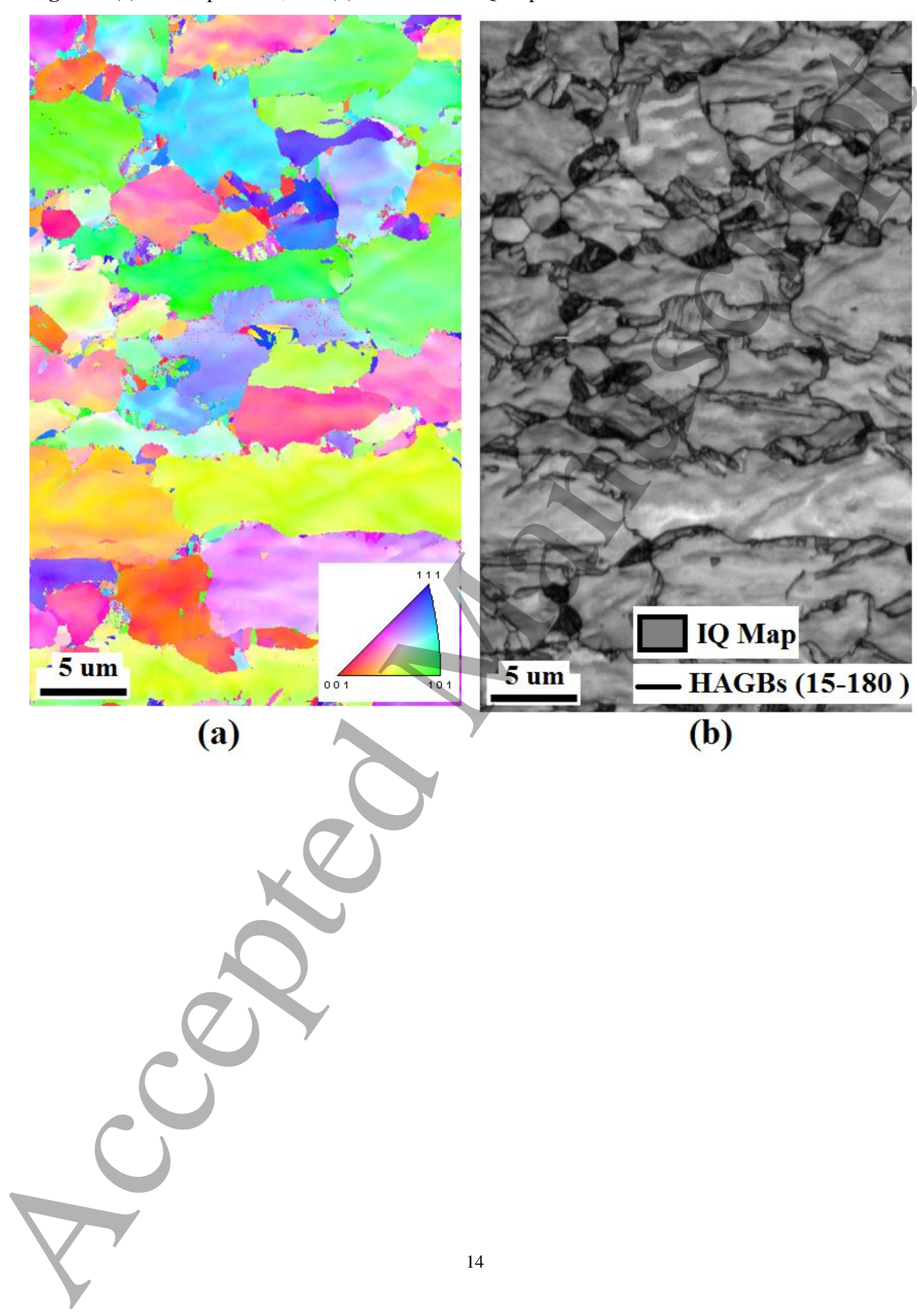
Figure 4 OM microstructure of (a) BM, (b) HAZ, (c) TMAZ and (d) SZ. (M=Martensite, $\mathrm{A}=$ Austenite, $\mathrm{B}=$ Bainite, $\mathrm{AF}=$ Allotriomorphic Ferrite, $\mathrm{WF}=$ Widmanstatten Ferrite)

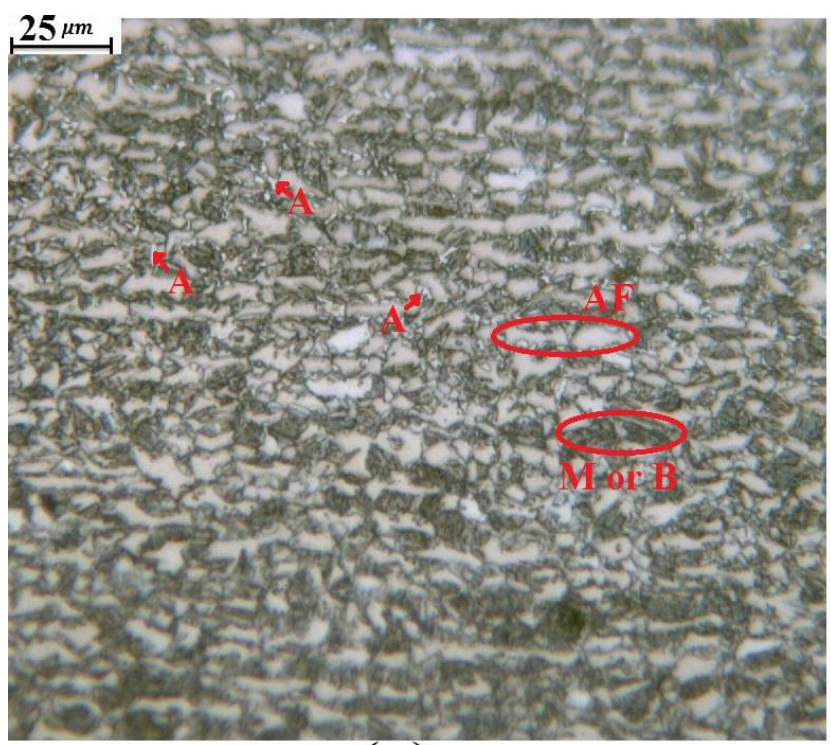

(a)

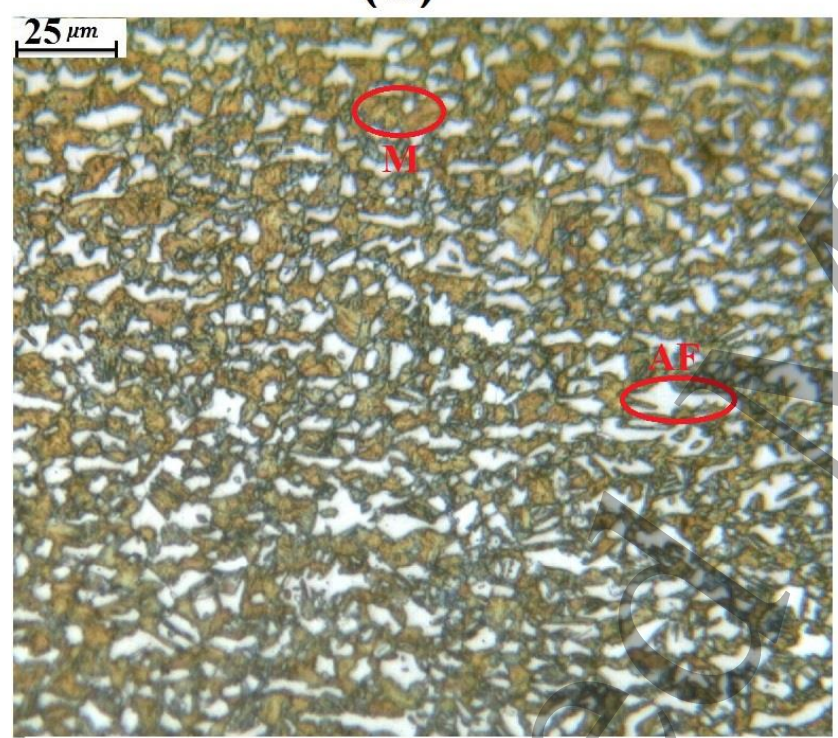

(c)

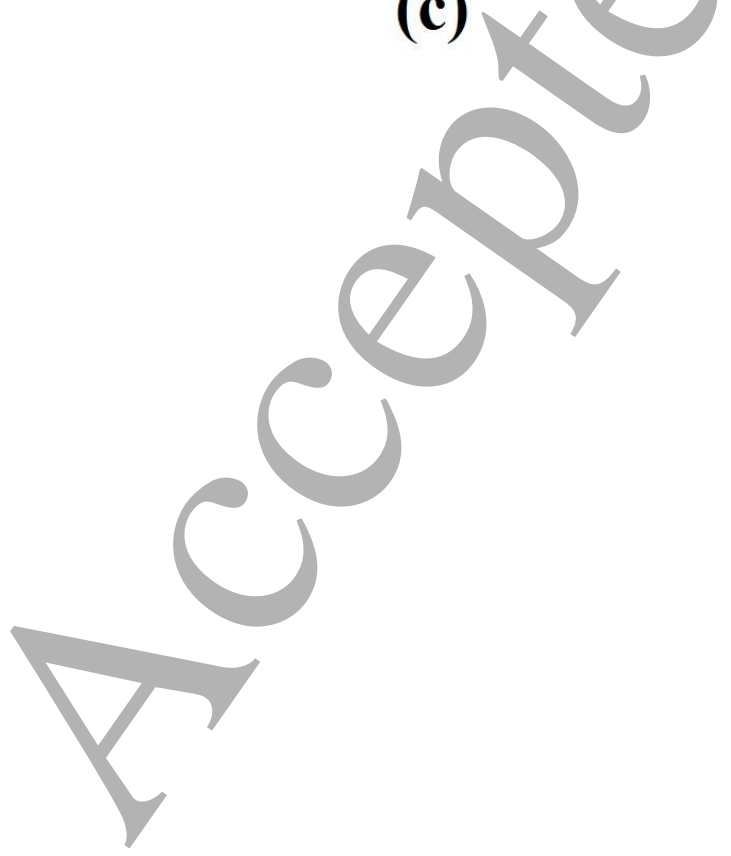

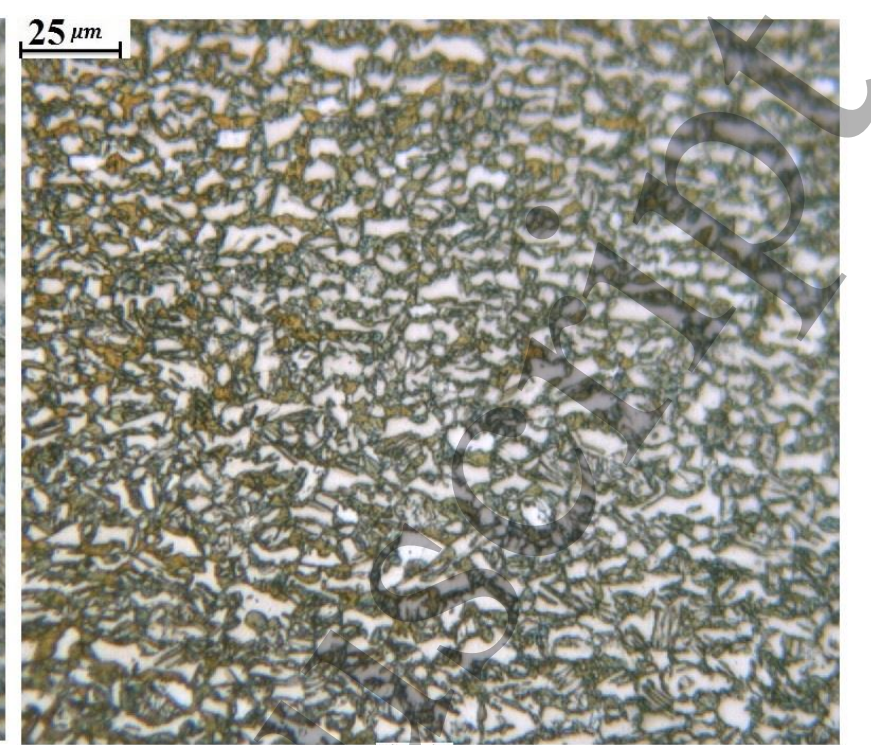

(b)

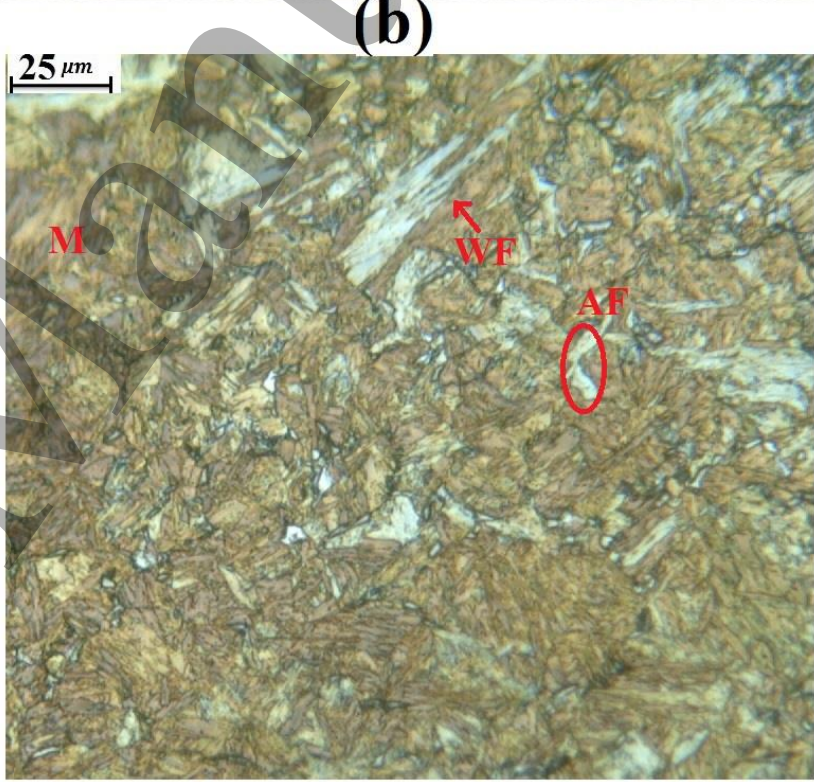

(d) 
Figure 5 (a) The section views of experimentally welded TRIP steel joints and (b) The section views of finite element models that indicate temperature and strain distribution in all case at the end of dwell time
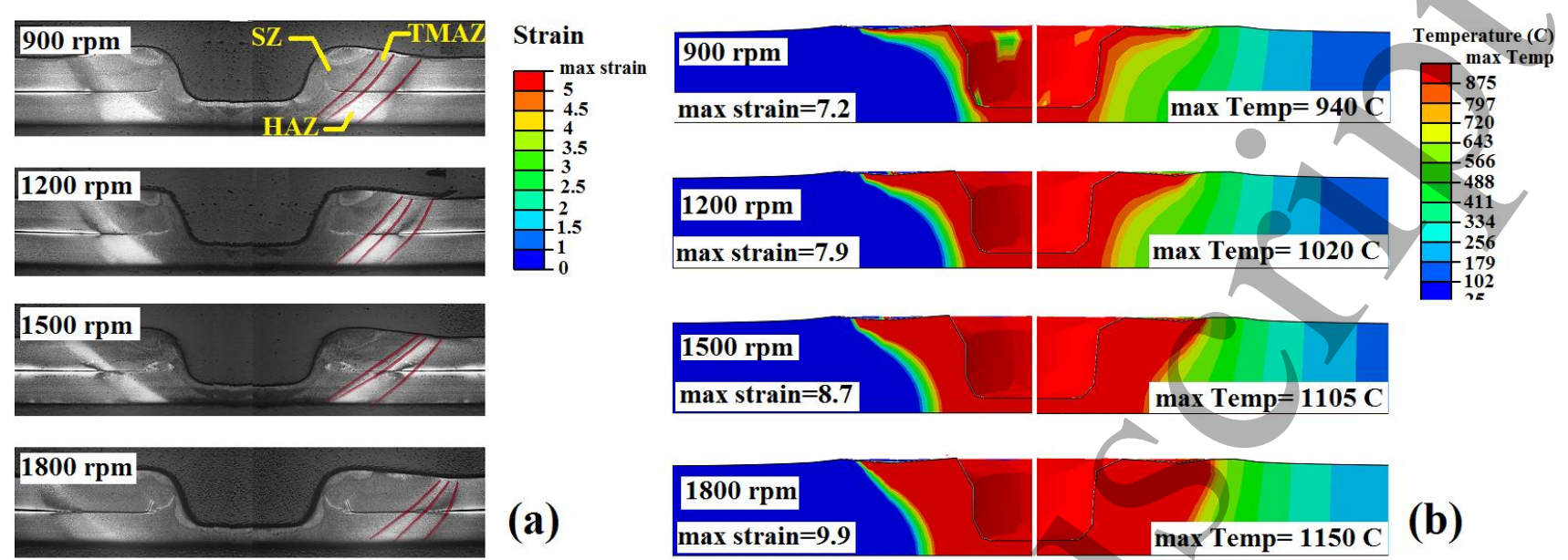

(a)

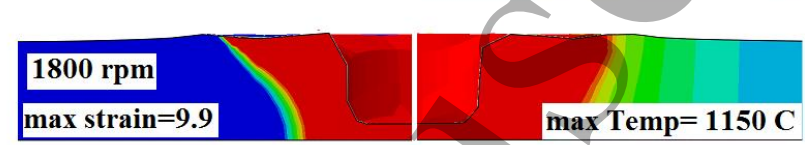

(b) 
Figure 6 FE-SEM micrograph TMAZ. (M=Martensite, A=Austenite, B=Bainite, $\mathrm{AF}=$ Allotriomorphic Ferrite)

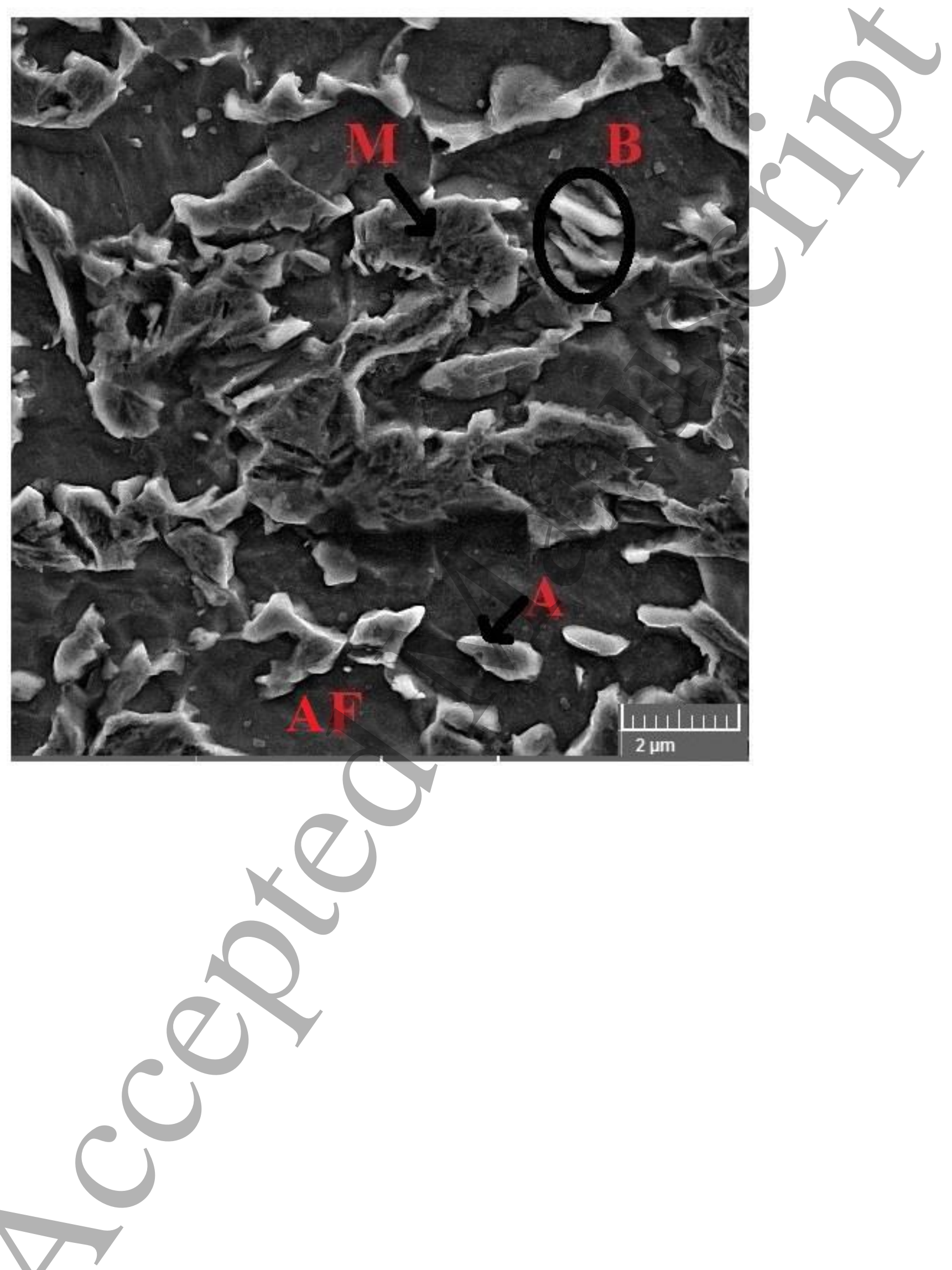


Figure 7 FE-SEM microstructure of SZs. (M=Martensite, AF=Allotriomorphic Ferrite, WF=Widmanstatten Ferrite)
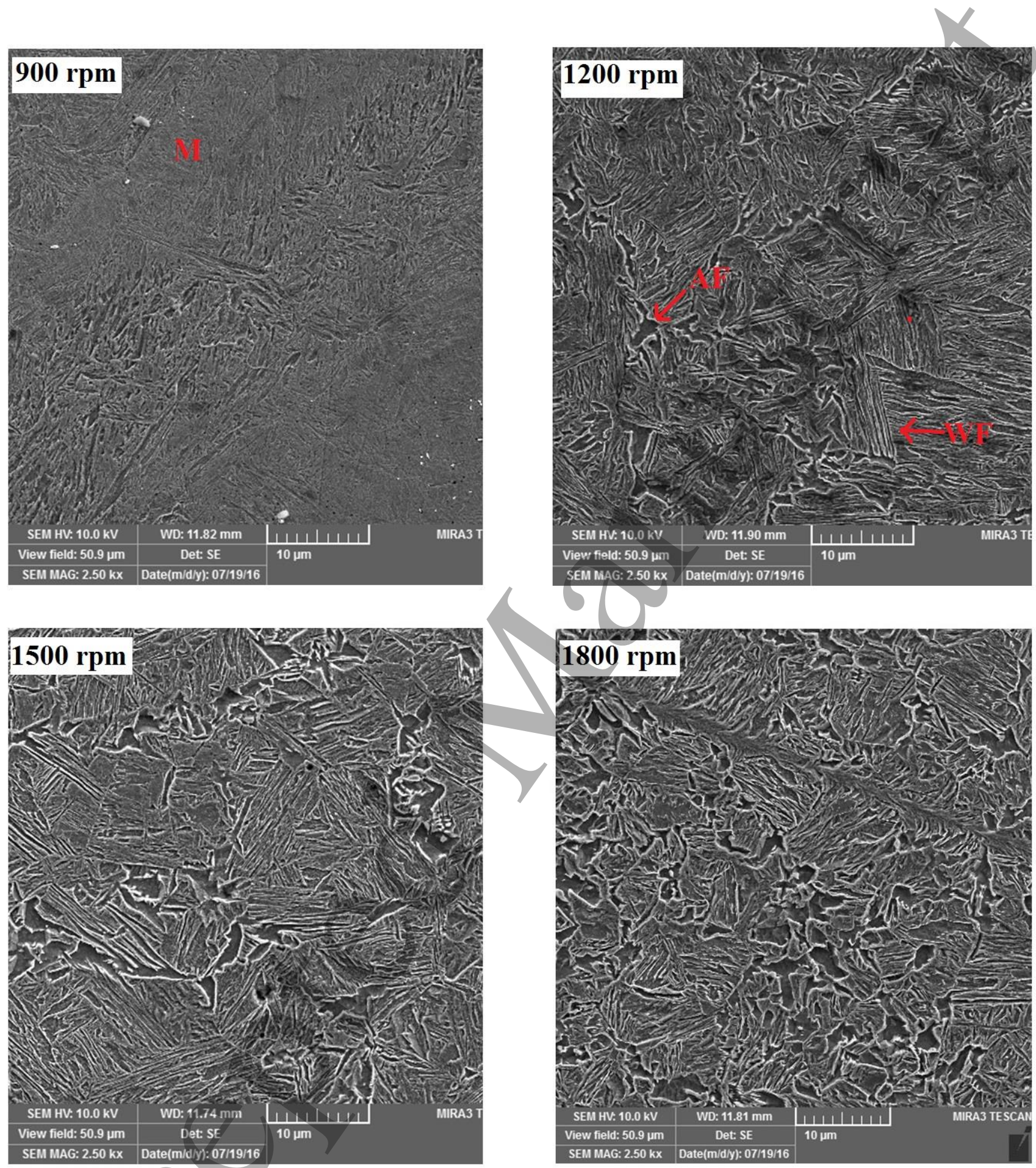
Figure 8 Thermal histories and cooling rates of SZs

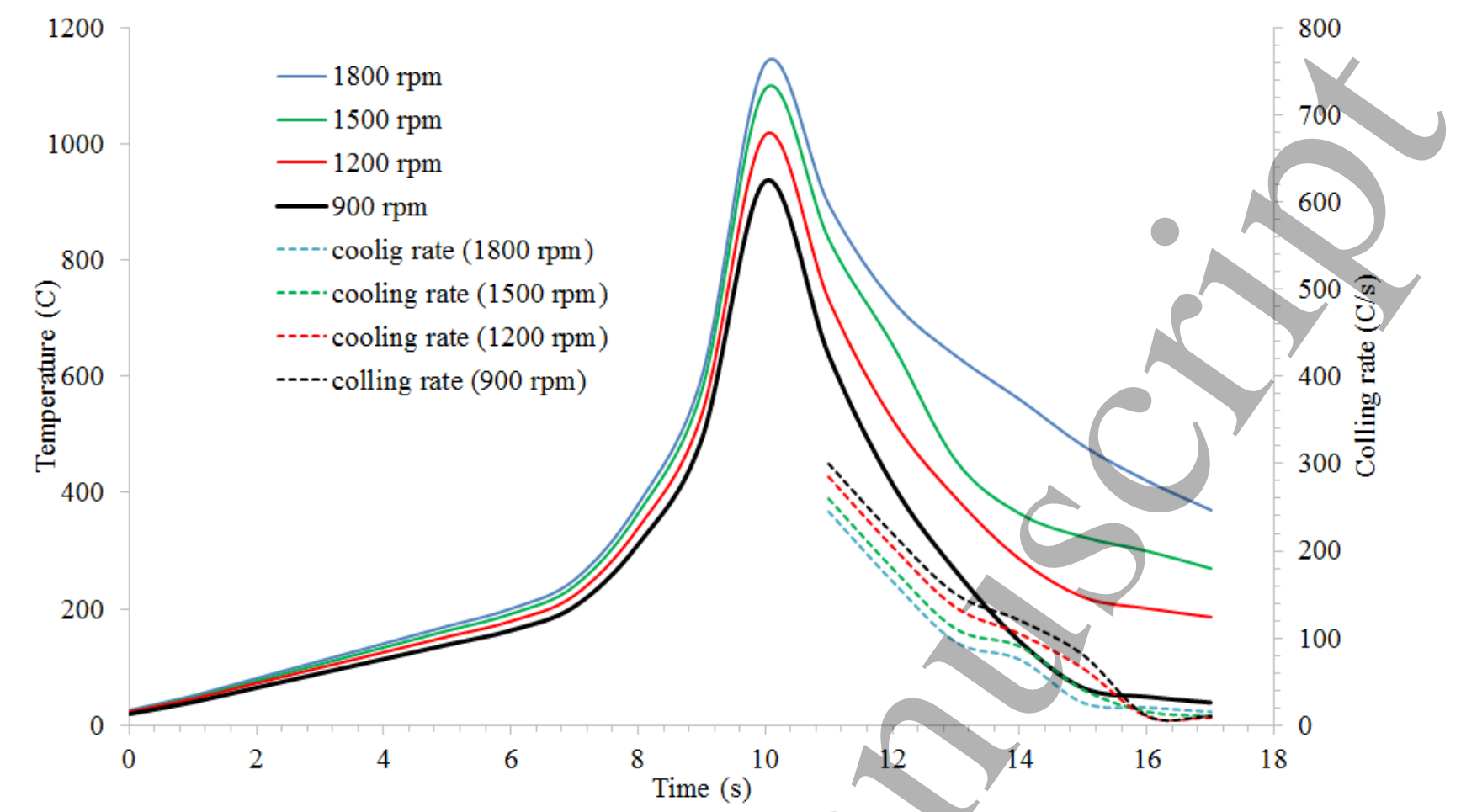


Figure 9 Vickers microhardness profiles of the four welded samples

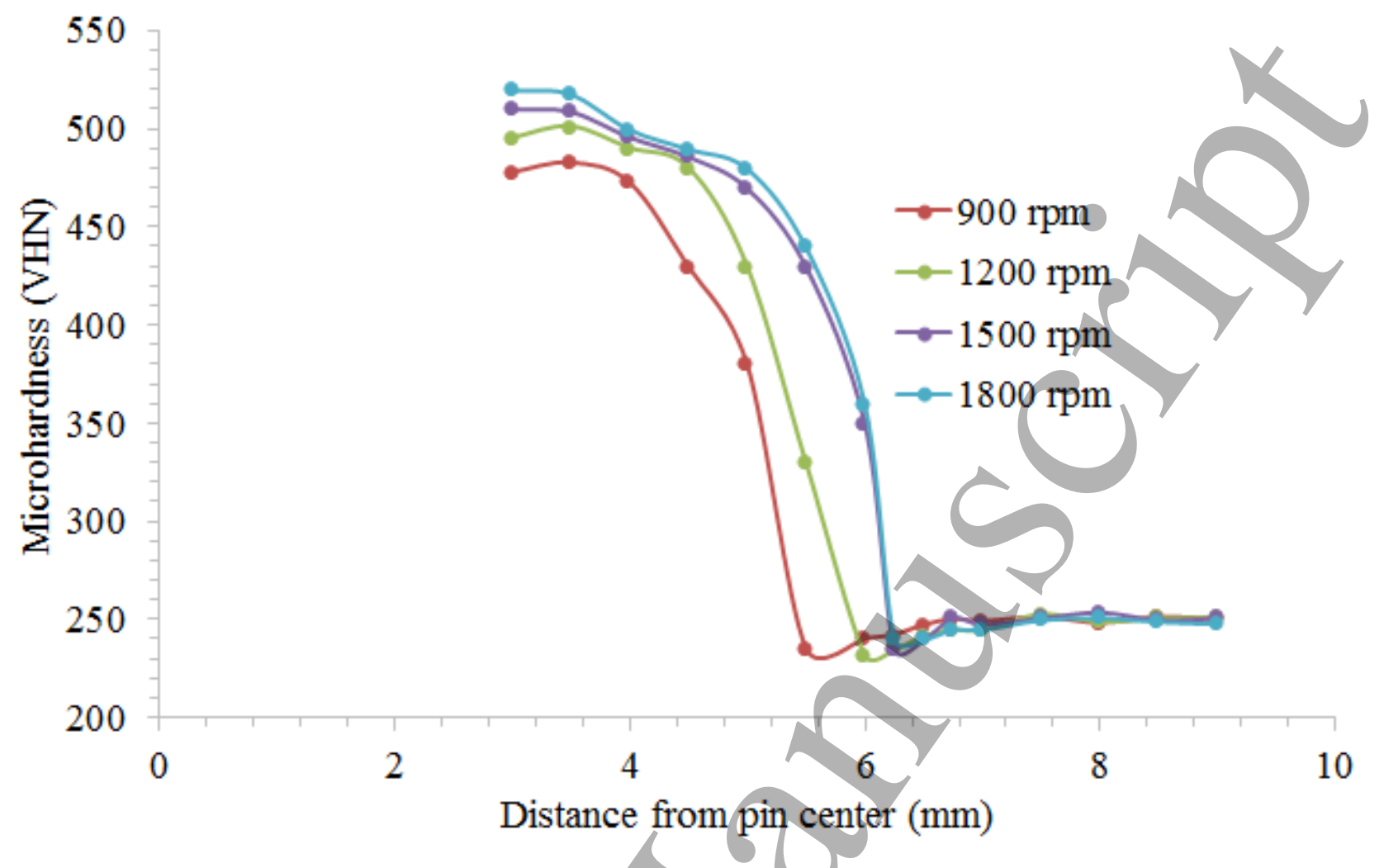


Figure 10 bonding ligament width of cases welded at rotational speed of (a) $1200 \mathrm{rpm}$ and (b) 1800 rpm

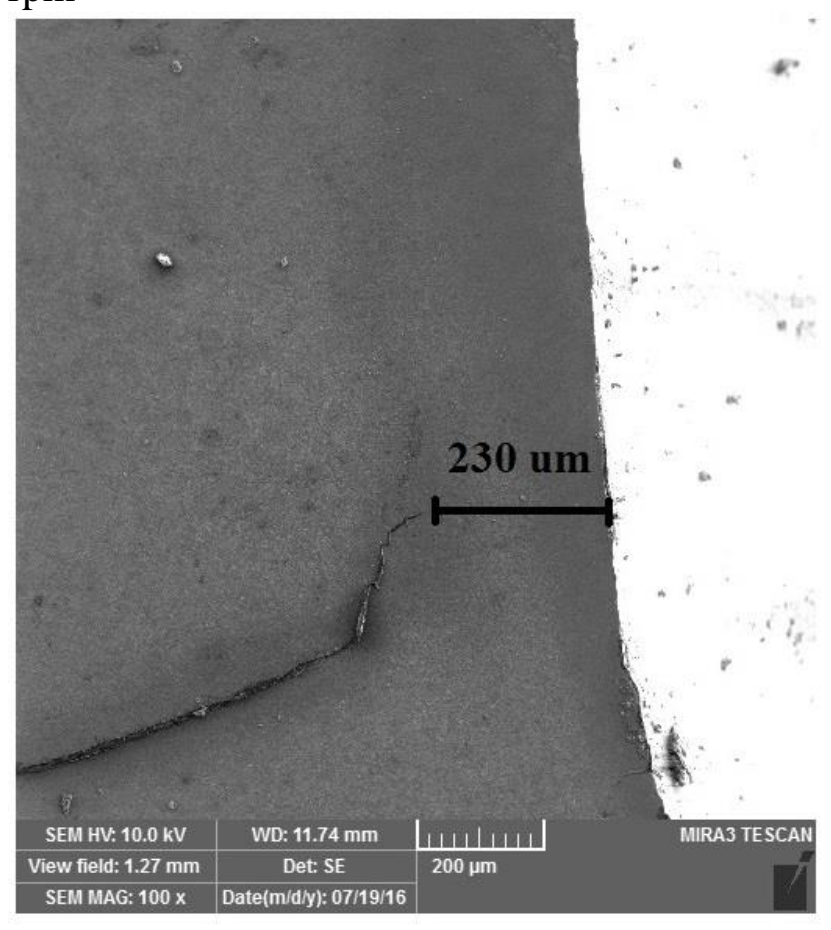

(a)

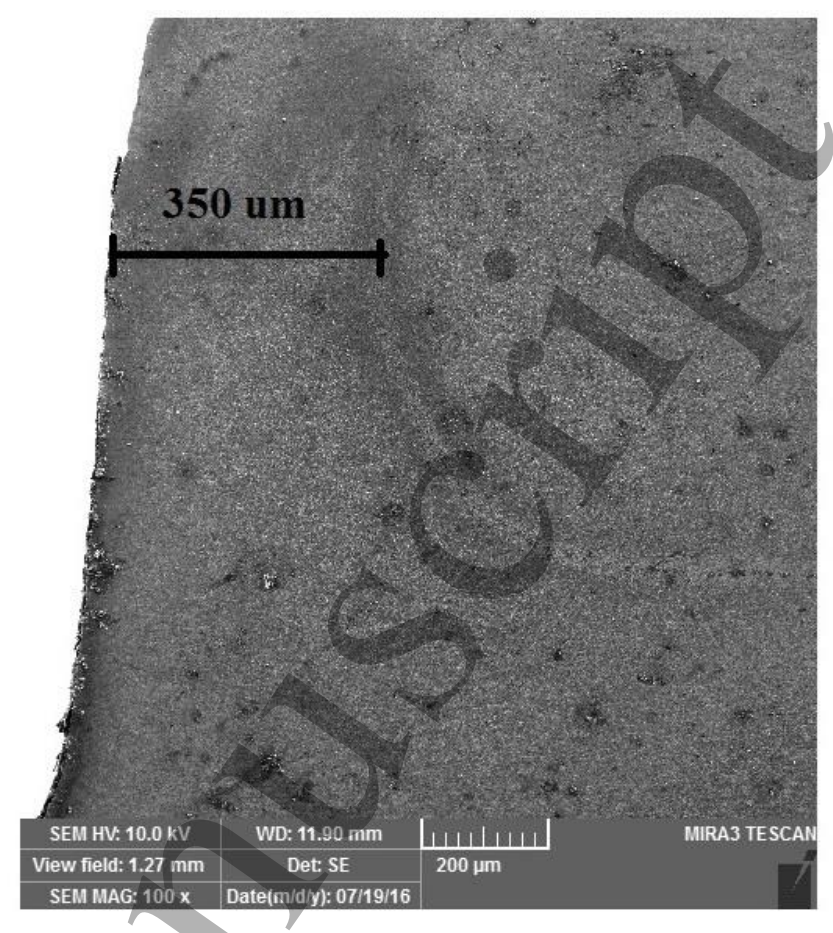

(b) 
Figure 11 FSSW responses at various rotational speeds

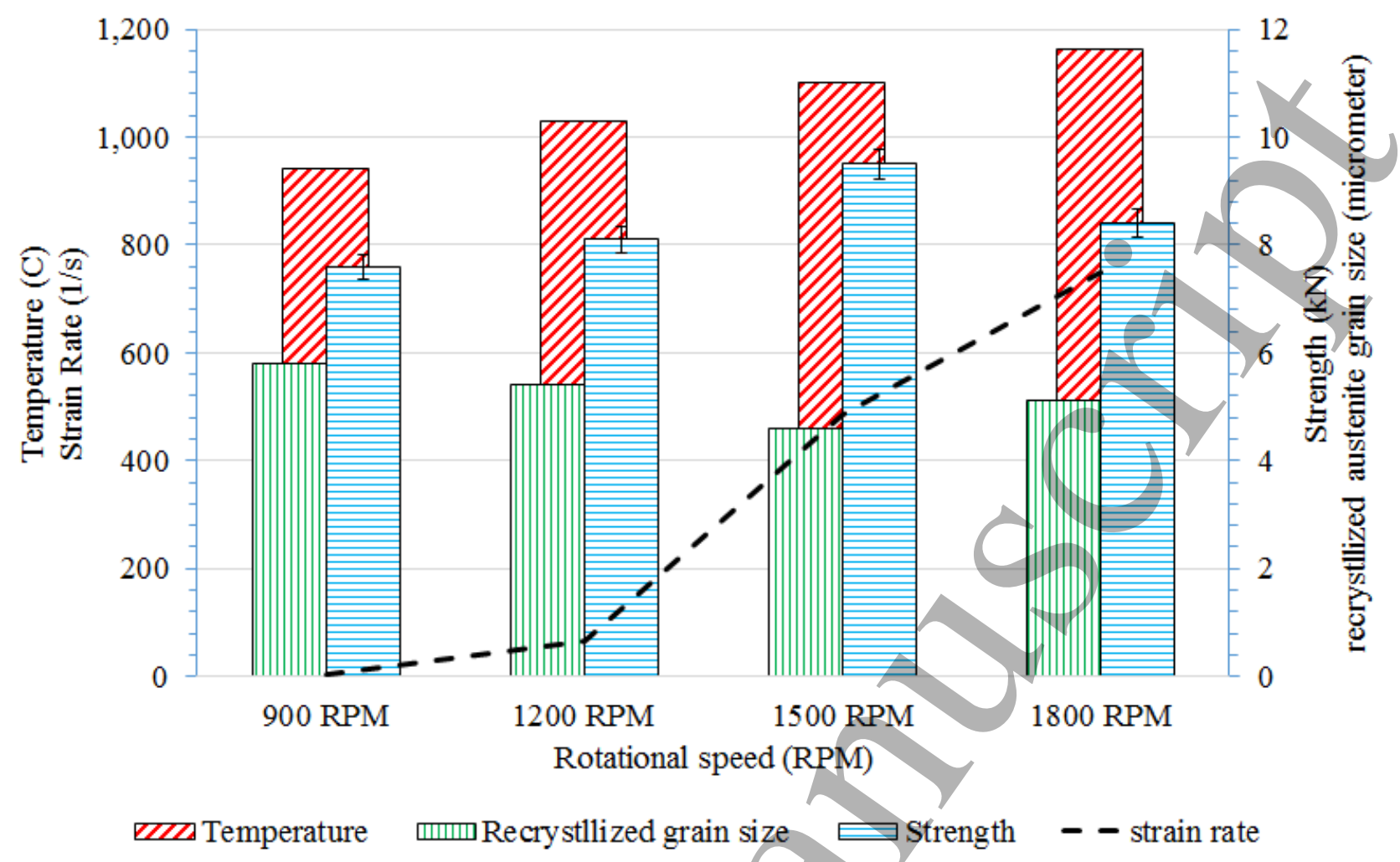


Figure 12 SEM micrographs of tensile shear fracture surface appearance of FSSWed TRIP steel (a) and (b) $1500 \mathrm{rpm}$ and, (c) and (d) $1800 \mathrm{rpm}$

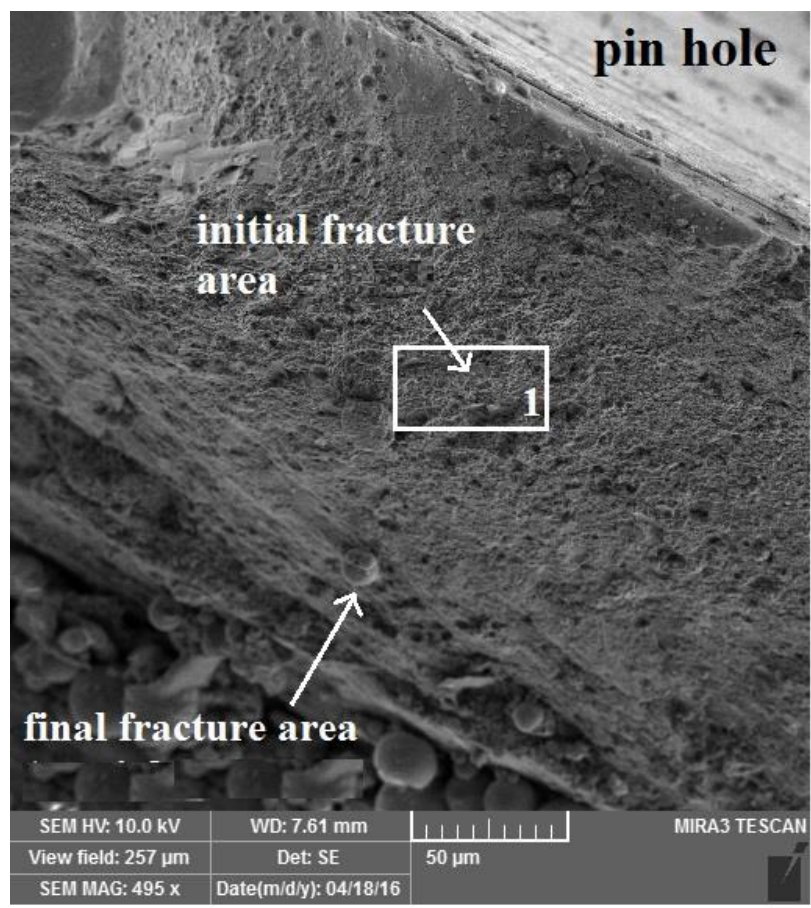

(a)

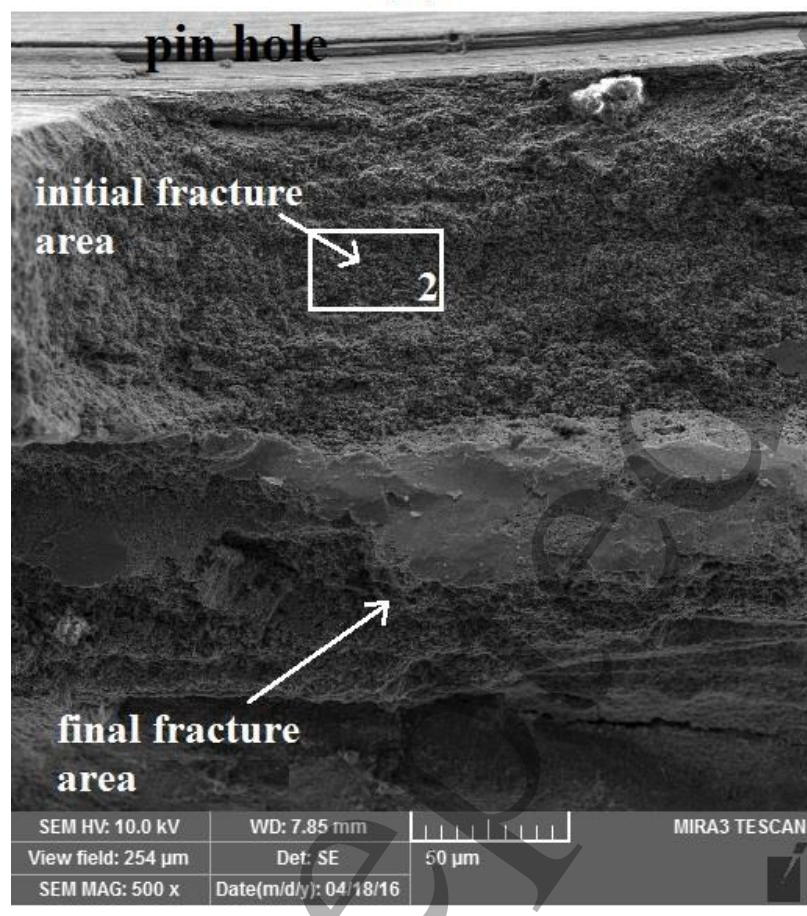

(c)

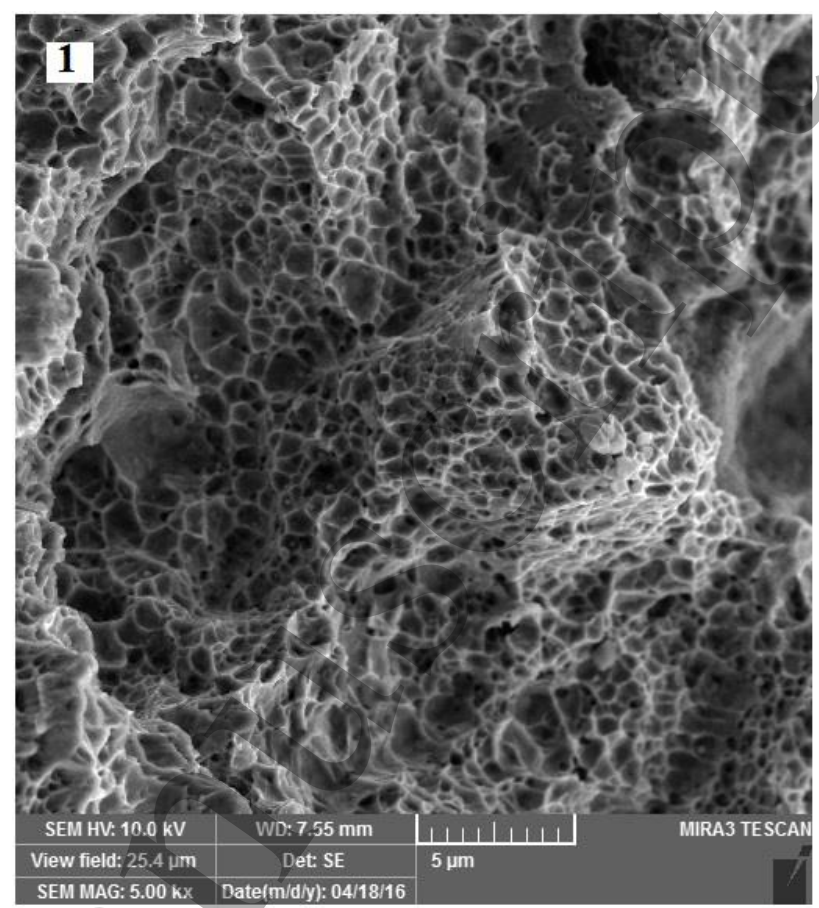

(b)

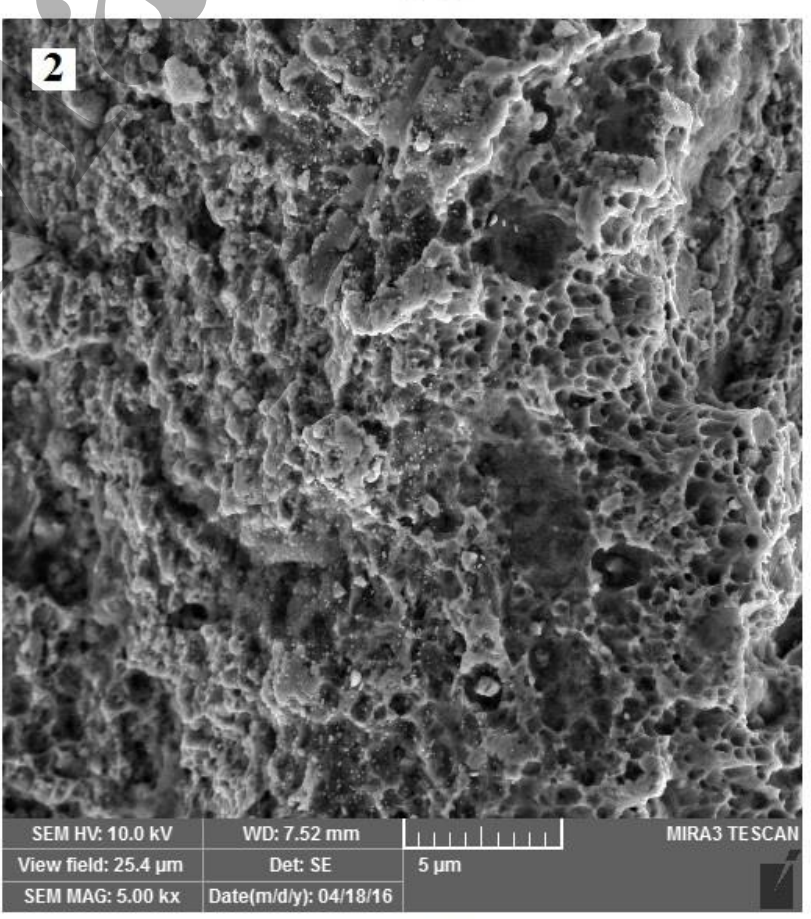

(d) 


\section{Table Captions}

Table 1 XRD results for volum fraction of retained austenite and its carbon content in all cases

\begin{tabular}{|c|c|c|c|c|c|c|}
\hline \multirow{2}{*}{$\begin{array}{c}\text { Rotational } \\
\text { speed }\end{array}$} & \multicolumn{2}{|c|}{ HAZ } & \multicolumn{2}{c|}{ TMAZ } & \multicolumn{2}{c|}{ SZ } \\
\cline { 2 - 7 } & $\begin{array}{c}\text { Austenite } \\
(\%)\end{array}$ & $\begin{array}{c}\text { C content } \\
(\mathrm{wt} \%)\end{array}$ & $\begin{array}{c}\text { Austenite } \\
(\%)\end{array}$ & $\begin{array}{c}\text { C content } \\
(\mathrm{wt} \%)\end{array}$ & $\begin{array}{c}\text { Austenite } \\
(\%)\end{array}$ & $\begin{array}{c}\text { C content } \\
(\mathrm{wt} \%)\end{array}$ \\
\hline $900 \mathrm{rpm}$ & 5.8 & 0.6 & 3.5 & 0.4 & - & - \\
\hline $1200 \mathrm{rpm}$ & 7.1 & 0.65 & 4.4 & 0.52 & - & - \\
\hline $1500 \mathrm{rpm}$ & 8.2 & 0.73 & 5.9 & 0.87 & 2.3 & 0.68 \\
\hline $1800 \mathrm{rpm}$ & 7.7 & 0.61 & 6.2 & 0.92 & 3.1 & 0.73 \\
\hline
\end{tabular}

